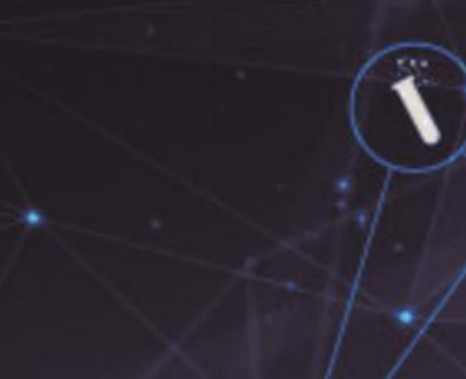

ARTIKEL RISET

http://citracendekiacelebes.org/index.php/INAJOH

\title{
Karakteristik pada Obesitas Berdasarkan Rentan Umur di Kelurahan Nganganaumala Kota Bau-Bau
}

\author{
Armanto Makmun ${ }^{1}$, Indri Meliawati Radisu ${ }^{2}$ \\ ${ }^{1}$ Departemen Ilmu Kesehatan Masyarakat, Fakultas Kedokteran, Universitas Muslim Indonesia \\ ${ }^{2}$ Program Studi Pendidikan Profesi Dokter, Fakultas Kedokteran, Universitas Muslim Indonesia \\ armanto.makmun@umi.ac.id ${ }^{1}$, indrimeliawati12@gmail.com ${ }^{2}$
}

\begin{abstract}
ABSTRAK
Obesitas adalah ketidakseimbangan jumlah makanan yang masuk dibandingkan dengan pengeluaran energi yang dilakukan oleh tubuh. Beberapa faktor penyebab obesitas antara lain gaya hidup, pola makan, dan aktivitas fisik. Obesitas pada usia dewasa membawa dampak pada kesehatan, dimana kenaikan berat badan dan obesitas menjadi salah satu faktor risiko untuk meningkatkan kejadian penyakit tidak menular. Tujuan dari penelitian ini untuk mengetahui hubungan antara rentan umur dengan kejadian obesitas. Metode: Penelitian ini merupakan desain penelitian deskriptif. Data yang dikumpulkan menggunakan kuesioner. Data penelitian ini berupa variabel kategorik dari 2 kelompok sehingga menggunakan uji Chi Square. Hasil pencarian referensi dimasukkan ke aplikasi Mendeley menggunakan sistem Vancouver. Hasil: jumlah total sampel sampel 98 orang dengan usia remaja 1119 tahun 7 orang $(7,1 \%)$, Dewasa $20-60$ tahun 88 orang $(89,8 \%)$, Lansia $>60$ tahun 3 orang $(3,2 \%)$. Berdasarkan jenis kelamin didapatkan laki-laki 18 orang $(18,4 \%)$ dan perempuan 80 orang $81,6 \%)$. Dan berdasarkan IMT didapatkan underweight 19 orang $(19,4 \%)$, normal 41 orang $(41,8 \%)$, overweight 12 orang (12,2\%), obes 123 orang (23,5\%), dan obes 23 orang (3,1\%). Kesimpulan: Tidak ada hubungan antara rentan umur dengan obesitas.
\end{abstract}

Kata kunci: Obesitas; Rentan Umur

\section{PUBLISHED BY :}

Yayasan Citra Cendekia Celebes

\section{Address :}

Perumahan Bukit Tamalanrea Permai

Blok D No.61 Kota Makassar,

Sulawesi Selatan, Kode Pos : 90211

Email :

inajoh@inajoh.org

Phone :

082346913176
Article history :

Received 09 Januari 2021

Received in revised form 09 Januari 2021

Accepted 02 Februari 2021

Available online 26 Februari 2021

licensed by Creative Commons Attribution-ShareAlike 4.0 International License. 


\section{ABSTRACT}

Background and Purpose: Obesity is an imbalance in the amount of food intake compared to energy expenditure carried out by the body. Some of the factors that cause obesity include lifestyle, diet and physical activity. Obesity in adulthood has an impact on health, where weight gain and obesity are risk factors for increasing the incidence of non-communicable diseases. The purpose of this study was to determine the relationship between age vulnerability and the incidence of obesity. Methods: This study is a descriptive research design. Data collected using a questionnaire. The data of this study were categorical variables from 2 groups so that it used the Chi Square test. Reference search results are entered into the Mendeley app using thesystem Vancouver. Results: The total sample size of 98 people with adolescence $11-19$ years 7 people (7.1\%), adults 20-60 years 88 people (89.8\%), elderly> 60 years 3 people (3.2\%). Based on gender, it was found that 18 men (18.4\%) and 80 women $81.6 \%)$. And based on BMI, it was found that 19 people were underweight (19.4\%), normal 41 people (41.8\%), overweight 12 people (12.2\%), obese 123 people (23.5\%), and obese 23 people (3.1\%). Conclusion: There is no relationship between age susceptibility to obesity.

Key words : Obesity; Age Vulnerable

\section{PENDAHULUAN}

Obesitas adalah ketidakseimbangan jumlah makanan yang masuk dibandingkan dengan pengeluaran energi yang dilakukan oleh tubuh.(1) Obesitas merupakan suatu keadaan dimana terjadi penumpukan lemak berlebih di dalam tubuh.(2) Obesitas pada usia dewasa membawa dampak pada kesehatan, dimana kenaikan berat badan dan obesitas menjadi salah satu faktor risiko untuk meningkatkan kejadian penyakit tidak menular seperti diabetes tipe 2, kanker dan beberapa penyakit kardiovaskular lainnya, bahkan hingga menyebabkan kematian di usia muda.(3)

Prevalensi obesitas di dunia dalam dua dekade terakhir mengalami peningkatan.(4) Di Indonesia, berdasarkan hasil Riset Kesehatan Dasar (RISKESDAS), menunjukkan peningkatan prevalensi obesitas pada penduduk > 18 tahun dari 11,7\% (2010) menjadi 15,4\% (2013). Riskesdas tahun 2013 juga menunjukkan disparitas prevalensi obesitas dari nilai prevalensi nasional pada beberapa provinsi di Indonesia. Peningkatan obesitas akan berdampak pada terjadinya peningkatan pembiayaan kesehatan.(5)

Beberapa faktor penyebab obesitas antara lain gaya hidup, pola makan, dan aktivitas fisik.(6) Faktor penyebab obesitas pada remaja bersifat multifaktorial. Peningkatan konsumsi makanan cepat saji (fast food), rendahnya aktivitas fisik, faktor genetik, pengaruh iklan, faktor psikologis, status sosial ekonomi, program diet, usia, dan jenis kelamin merupakan faktor-faktor yang berkontribusi pada perubahan keseimbangan energi dan berujung pada kejadian obesitas.(7)

Obesitas pada usia dewasa dapat secara langsung berdampak pada peningkatan beban ekonomi suatu negara. Biaya pengeluaran medis penurunan aktivitas fisik dan peningkatan jumlah ketidakhadiran di tempat kerja terkait penyakit yang ditimbulkan oleh obesitas dapat dijadikan tolak ukur penurunan produktivitas suatu Negara. Karyawan atau buruh yang memiliki obesitas membutuhkan waktu yang lebih untuk menyelesaikan tugas dan keterbatasan kemampuan dalam 
melakukan pekerjaan fisik. Sedangkan pada karyawan atau buruh yang memiliki berat badan normal tidak memiliki atau sedikit gangguan terkait kesehatan.(8)

\section{METODE}

Penelitian ini merupakan desain penelitian deskriptif. Lokasi penelitian di FK UMI Makassar, Sulawesi Selatan dan waktu penelitian dilaksanakan pada 4-5 Januari 2021. Populasi adalah masyarakat Kelurahan Nganganaumala Kota Bau-Bau dengan teknik sampling menggunakan simple random sampling. Berdasarkan cara memperoleh data, data yang dikumpulkan menggunakan kuesioner. Analisis data yang diperoleh dilakukan menggunakan Microsoft Excel dan IBM SPSS. Hasil pencarian referensi dimasukkan ke aplikasi Mendeley menggunakan sistem Vancouver.

\section{HASIL}

Tabel 1. Karakteristik responden

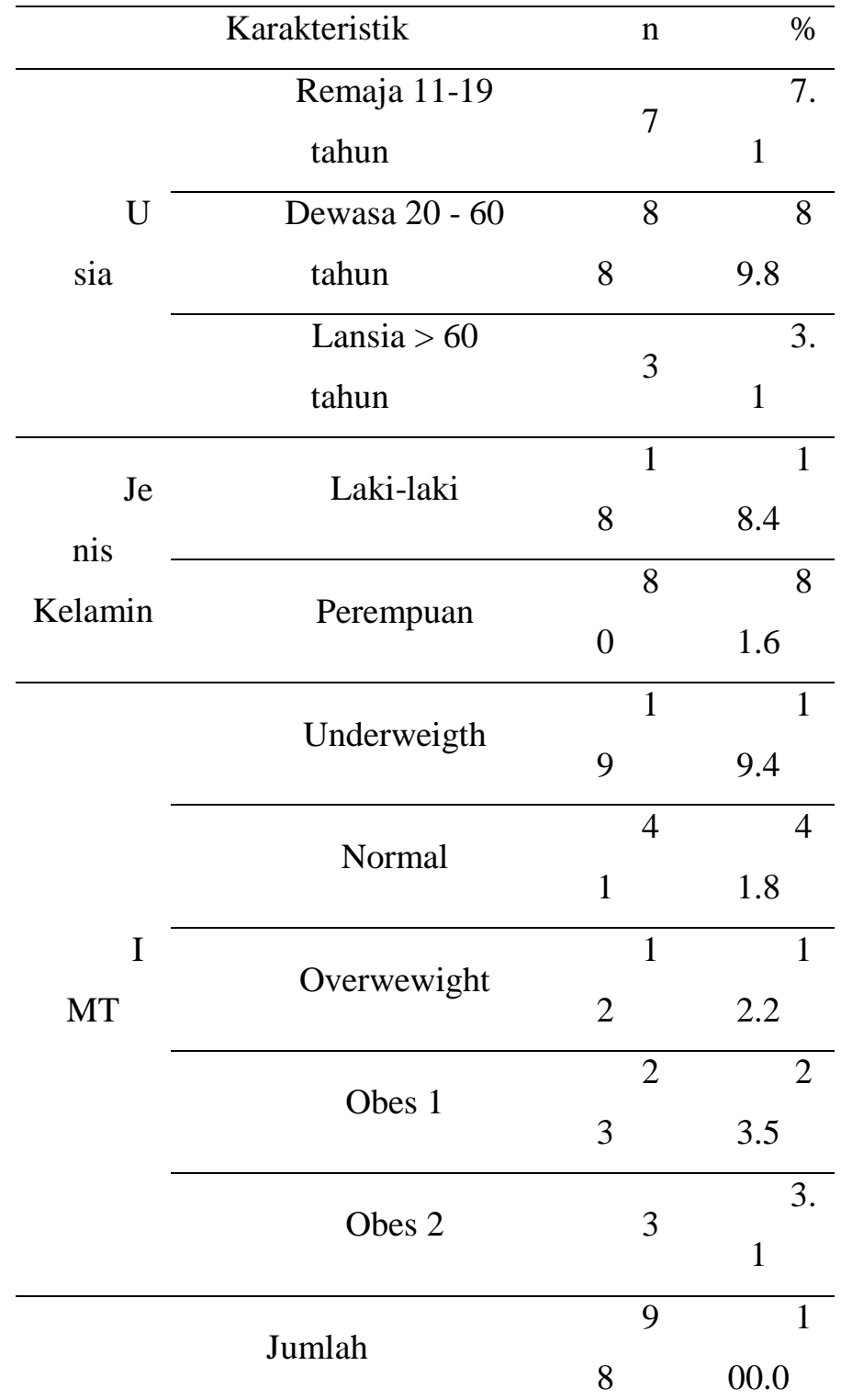

Pada tabel 1 menunjukkan jumlah total sampel 98 orang dengan usia remaja 11-19 tahun 7 orang $(7,1 \%)$, dewasa $20-60$ tahun 88 orang $(89,8 \%)$, lansia $>60$ tahun 3 orang $(3,2 \%)$. Berdasarkan 
jenis kelamin didapatkan laki-laki 18 orang $(18,4 \%)$ dan perempuan 80 orang $81,6 \%$ ). Dan berdasarkan IMT didapatkan underweight 19 orang $(19,4 \%)$, normal 41 orang $(41,8 \%)$, overweight 12 orang (12,2\%), obes 123 orang (23,5\%), dan obes 23 orang $(3,1 \%)$.

Tabel 2. Hubungan IMT dengan rentan usia WHO

\begin{tabular}{|c|c|c|c|c|c|c|c|}
\hline \multirow[b]{2}{*}{ Usi } & & \multicolumn{5}{|c|}{ IMT } & \multirow{2}{*}{$\begin{array}{r}\text { J } \\
\text { umlah }\end{array}$} \\
\hline & & $\begin{array}{l}\text { Under } \\
\text { weigth }\end{array}$ & $\begin{array}{l}\text { Nor } \\
\text { mal }\end{array}$ & $\begin{array}{l}\text { Overw } \\
\text { ewight }\end{array}$ & $\begin{array}{l}\text { Obes } \\
1\end{array}$ & $2^{\text {Obes }}$ & \\
\hline \multirow{2}{*}{$\begin{array}{l}\text { Remaj } \\
\text { a } 11-19 \\
\text { tahun }\end{array}$} & $\mathrm{n}$ & 4 & 2 & 0 & 1 & 0 & 7 \\
\hline & $\%$ & $57.1 \%$ & $\%^{28.6}$ & $0.0 \%$ & $\%^{14.3}$ & $0.0 \%$ & $\begin{array}{r}1 \\
00.0 \% \\
\end{array}$ \\
\hline \multirow{2}{*}{$\begin{array}{l}\text { Dewas } \\
\text { a } 20-60 \\
\text { tahun }\end{array}$} & $\mathrm{n}$ & 15 & 39 & 11 & 20 & 3 & $8^{8}$ \\
\hline & $\%$ & $17.0 \%$ & $\%^{44.3}$ & $12.5 \%$ & $\%^{22.7}$ & $3.4 \%$ & $\begin{array}{r}1 \\
00.0 \% \\
\end{array}$ \\
\hline \multirow{2}{*}{$\begin{array}{l}\text { Lansia } \\
>60 \text { tahun }\end{array}$} & $\mathrm{n}$ & 0 & 0 & 1 & 2 & 0 & 3 \\
\hline & $\%$ & $0.0 \%$ & $0.0 \%$ & $33.3 \%$ & $\%^{66.7}$ & $0.0 \%$ & $\begin{array}{r}1 \\
00.0 \% \\
\end{array}$ \\
\hline \multirow{2}{*}{$\begin{array}{l}\text { Jumla } \\
\mathrm{h}\end{array}$} & $\mathrm{n}$ & 19 & 41 & 12 & 23 & 3 & $8^{9}$ \\
\hline & $\%$ & $19.4 \%$ & $\%^{41.8}$ & $12.2 \%$ & $\%^{23.5}$ & $3.1 \%$ & $\begin{array}{r}1 \\
00.0 \%\end{array}$ \\
\hline
\end{tabular}

Pada tabel 2 menunjukkan IMT pada usia remaja 11-19 tahun 4 orang underweight, 2 orang normal, dan 1 orang yang obes 1 . Pada usia dewasa 20-60 tahun 15 orang underweight, 39 orang normal, 11 orang overweight, 20 orang obes 1 , dan 3 orang obes 2 . Pada usia lansia $>60$ tahun 1 orang underweight, 2 orang obes 1.

\section{PEMBAHASAN}

Berdasarkan hasil penelitian ini rentan umur berpengaruh dengan kejadian obesitas, yang dimana semakin bertambah umur semakin berisiko mengalami obesitas. Hal ini sejalan dengan penelitian sebelumnya bahwa umur ada hubungan antara umur dengan kejadian obesitas proporsi anggota keluarga yang mengalami obesitas lebih banyak ditemukan pada kelompok umur $\geq 25$ tahun dibandingkan dengan umur $<25$ tahun.(9)

Kegemukan merupakan akibat dari kelebihan lemak tubuh karena tidak adanya keseimbangan antara kalori yang dikonsumsi dan energi yang dikeluarkan dan sering kali menyebabkan gangguan kesehatan.(9) Seiring bertambahnya usia, proses metabolisme tubuh akan cenderung menurun yang akan menyebabkan fungsi otot menurun dan kadar lemak tubuh meningkat. Jika tidak diimbangi dengan gaya hidup sehat, seperti pengaturan pola makan dan aktivitas fisik, maka akan terjadi penumpukan lemak tubuh, terutama lemak di abdomen yang akan meningkatkan resiko terjadinya obesitas abdominal.(10) 
Pada lanjut usia, tubuh akan mengalami penurunan massa otot dan perubahan hormon sehingga terjadi penurunan metabolisme dalam tubuh. Pada usia ini cenderung mengalami penurunan fungsi organ tubuh akibat proses degeneratif (penuaan) sehingga dapat mendorong terjadinya penyakit tidak menular. Penurunan fungsi fisiologis berdampak pada menurunnya aktivitas fisik sehingga kemungkinan untuk terjadi obesitas lebih besar.(6)

Beberapa faktor penyebab obesitas antara lain gaya hidup, pola makan, dan aktivitas fisik.(6) Faktor genetik berhubungan dengan pertambahan berat badan, IMT, lingkar pinggang,dan aktivitas fisik. Jika ayah dan/atau ibu menderita overweight (kelebihan berat badan) maka kemungkinan anaknya memiliki kelebihan berat badan sebesar 40-50\%. Faktor penyebab obesitas pada anak lainnya yaitu asupan makanan berlebih yang berasal dari jenis makanan olahan serba instan, minuman soft drink dan makanan jajanan seperti cepat saji (burger, pizza, hotdog) serta makanan siap saji lainnya yang tersedia di gerai makanan.(11)

\section{KESIMPULAN DAN SARAN}

Obesitas merupakan suatu keadaan dimana terjadi penumpukan lemak berlebih di dalam tubuh. Beberapa faktor penyebab obesitas antara lain gaya hidup, pola makan, dan aktivitas fisik. Obesitas pada usia dewasa membawa dampak pada kesehatan, dimana kenaikan berat badan dan obesitas menjadi salah satu faktor risiko untuk meningkatkan kejadian penyakit tidak menular. Pada penelitian ini didapatkan hasil bahwa ada hubungan antara rentan umur dengan obesitas. Hasil ini diperkuat dengan temuan dari beberapa penelitian sebelumnya yang menyatakan ada hubungan antara rentan umur dengan obesitas. Diharapkan bagi peneliti selanjutnya agar dapat meneliti lebih lanjut.

\section{UCAPAN TERIMA KASIH}

Puji syukur kepada Allah SWT, karena atas segala rahmat dan bimbingan-Nya penulis dapat menyelesaikan Karya Tulis Ilmiah ini. Penulis juga berterima kasih kepada peneliti-peneliti sebelumnya, dosen pembimbing, keluarga serta teman-teman yang senantiasa memberikan do'a dan dukungan sehingga penulisan hasil karya tulis ilmiah ini dapat terselesaikan.

\section{DAFTAR PUSTAKA}

1. Masyarakat JK. Faktor-Faktor Yang Berhubungan Dengan Kejadian Obesitas Pada Karyawati Perusahaan Di Bidang Telekomunikasi Jakarta Tahun 2017. J Kesehat Masy. 2017;5(3):193-201.

2. Sofa IM. Kejadian Obesitas, Obesitas Sentral, dan Kelebihan Lemak Viseral pada Lansia Wanita. Amerta Nutr. 2018;2(3):228.

3. Safitri DE, Rahayu NS. Determinan Status Gizi Obesitas pada Orang Dewasa di Perkotaan: Tinjauan Sistematis The Determinants of Urban A dults ' Obesity : Systematic review. Arkesmas. 2020;5(1):1-15.

4. Sudikno S, Syarief H, Dwiriani CM, Riyadi H. Faktor Risiko Obesitas Sentral Pada Orang Dewasa Umur 25-65 Tahun Di Indonesia (Analisis Data Riset Kesehatan Dasar 2013). Penelit 
Gizi dan Makanan (The J Nutr Food Res. 2016;38(2).

5. Kementrian Kesehatan RI. Panduan Pelaksanaan Gerakan Nusantara Tekan Angka Obesitas (GENTAS) [Internet]. 2017. p. 32. Available from: http://p2ptm.kemkes.go.id/dokumen$\mathrm{ptm} /$ panduan-gentas

6. Nugroho KPA, Triandhini RLNKR, Haika SM. Identifikasi Kejadian Obesitas Pada Lansia Di Wilayah Kerja Puskesmas Sidorejo Kidul. Media Ilmu Kesehat. 2019;7(3):213-22.

7. Kurdanti W, Suryani I, Syamsiatun NH, Siwi LP, Adityanti MM, Mustikaningsih D, et al. Faktorfaktor yang mempengaruhi kejadian obesitas pada remaja. J Gizi Klin Indones. 2015;11(4):179.

8. Sanchez Bustillos A, Vargas KG, Gomero-Cuadra R. Work productivity among adults with varied Body Mass Index: Results from a Canadian population-based survey. J Epidemiol Glob Health. 2015;5(2):191-9.

9. Nadimin, Ayumar, Fajarwati. Obesitas Pada Orang Dewasa Anggotan Keluarga Miskin Di Kecamatan Lembang Kabupaten Pinrang. Media Kesehat Masy Indones Univ Hasanuddin. 2015;11(3):147-53.

10. Nurrahmawati F, Fatmaningrum W. Hubungan Usia, Stres, dan Asupan Zat Gizi Makro dengan Kejadian Obesitas Abdominal pada Ibu Rumah Tangga di Kelurahan Sidotopo, Surabaya. Amerta Nutr. 2018;2(3):254.

11. Dewi MC. Faktor-Faktor yang Menyebabkan Obesitas pada Anak. Majority. 2015;4(8):53-6. 